\title{
Hypoplastic left heart syndrome [HLHS]: treatment options in present era
}

\author{
Vivek Rai ${ }^{1}$ (D) $\cdot$ Marcin Gładki ${ }^{1} \cdot$ Mirosława Dudyńska $^{1} \cdot$ Janusz Skalski ${ }^{1}$
}

Received: 13 June 2018 /Revised: 2 September 2018 / Accepted: 7 September 2018 / Published online: 31 October 2018

(C) The Author(s) 2018

\begin{abstract}
Hypoplastic left heart syndrome (HLHS) is the most severe form of congenital heart defect (CHD). The first successful intervention for it was undertaken by Norwood in 1983. Since then, there have been much development in the pre, intra, and postoperative treatment option in staged palliative surgical procedures. Early diagnostic management, prenatal interventions, innovative diagnostic methods, constantly modified surgical techniques, and hybridization contribute to a significant progress in treatment options. This will allow for defining an optimal strategy of improving survival and quality of life in HLHS patients. The development of intervention cardiology makes possible the stepwise treatment of the defect with one operation only. The first and third stage may be done by hybrid or interventional methods, then only the second stage of treatment needs to be done surgically. The world experience and all the available literature says that the 1st-stage procedure could be done now safely either directly or with a bridge to Norwood followed by the stage 2 with a Glen or Hemi-Fontan and followed by a Fontan down the lane surgically.
\end{abstract}

Keywords Congenital heart defect $\cdot$ Single ventricle $\cdot$ Hypoplastic left heart syndrome

\section{Introduction}

HLHS is the most severe form of CHD, representing cardiac malformations that are characterized by severe underdevelopment of the structures in the left heart-aorta complex, including the left ventricular cavity and mass. The term potentially denotes any malformation that involves underdevelopment of the left-sided cardiac structures from aortic stenosis and coarctation of the aorta to the other extremes involving aortic atresia, mitral atresia, and hypoplasia of the ascending aorta. Statistically, about $1.25 \%$ children with congenital heart defects are patients with single ventricle heart [1]. The majority of untreated newborns die within the first 7-10 days of life.

Vivek Rai

vivraze@gmail.com

1 Department of Pediatric Cardiac Surgery, Jagiellonian University Children's Hospital, Ul. Wielicka 265, 30-663 Krakow, Poland

\section{Prenatal diagnosis}

Development in the field of ultrasonography has allowed for recognizing early HLHS in the first trimester of fetal life, which helps in further planning and making decision whether to proceed with pregnancy. Anatomical defects in HLHS which worsen the prognosis are restrictive atrial connection, tricuspid regurgitation, and ventricular dysfunction [2]. The percentage of neurological complications is lower, due to early recognizing HLHS [3]. In some countries, where pregnancy termination rates are relatively high, a higher number of prenatal diagnoses caused a decrease in the birth rate of children with HLHS [4]. Fetal interventions in HLHS have been developed in order to improve hemodynamics and prevent the development of defects. Currently, two types of treatment are used in case of this defect: balloon septostomy in case of restrictions of the atrial septum and balloon valve surgery in cases of critical aortic stenosis. In both cases, the treatment is performed under guidance of ultrasound (fetal echocardiography). The procedure must be done in very experienced centers because in $20 \%$ of such interventions, loss of the fetus is involved [5].

During prenatal intervention, it is also possible to perform a thorough genetic diagnostic management. Indeed, 
the cause of the defect is multifactorial and not stable. The established risk of recurrence of the defect in future pregnancies is $2-4 \%$, and in families with two children with this disadvantage, it reaches $25 \%$ [6].

\section{Heart transplant}

Heart transplant in a newborn with HLHS is also an available treatment option. The procedure always entails the risk of organ rejection and complications associated with immunosuppression [infection, tumor]. In the present era, this method is still limited due to scarcity of donors [7]. In newborns, hearts to be transplanted may be harvested from noncompliant donors (ABO-incompatible), thanks to the immature immune system in neonates [8]. The quality of life after heart transplant is better as compared to patients with staged palliative surgery [9].

Heart transplantation is also a possible treatment modality in cases of extreme heart failure after the Fontan procedure, especially when the background is dysfunction of the ventricle. This is a high-risk procedure in patients being treated by heart transplant, but if successful, it provides a good quality of life in this group of patients [10]. Ventricular assist device (VAD) support can be used as a bridge to transplant in HLHS patients.

\section{Palliative treatment}

Palliative treatment is the most commonly used method of treatment. This method includes three stages of treatment. The first stage called the Norwood operation takes place in the neonatal period, the second stage is the hemi-Fontan (HF) or Glenn procedures performed at around 4-6 months of life, and the final stage is the Fontan operation which takes place around 18-24 months of age [11]. Since 1983, there has been much advancement in pre, intra, and postoperative care in HLHS. With progress in the field of cardiac surgery and introduction of various modifications in the stage treatment, there is a significant improvement in survival rates [12]. Despite improving results and more surgical procedures, children with HLHS require constant multispecialty adapting care.

\section{Norwood procedure}

The aim of this procedure is to use the right ventricle as the main pumping ventricle for systemic circulation. To achieve this goal, the following steps in the operation are taken: i. Connection between the right ventricle and aorta is created with the aid of a pulmonary homograft (neoaorta).

ii. Developing a new source of pulmonary blood flow via the systemic-to-pulmonary artery shunt: modifed BlalockTaussig (MBT) shunt or right ventricle-to-pulmonary artery (RV-PA) shunt. The shunt is a long-term replacement for prostaglandin E1 (PGE1), which was used preoperatively for PGE1-dependent ductus arteriosus (DA) patency.

iii. An atrial septectomy to secure good atrial communication, which is required to permit pulmonary venous return to reach the right ventricle. If restrictive atrial septum is present, then the Rashkind procedure along with stent implantation should be performed.

At conclusion, the right ventricle provides blood to both circulation systems in parallel, as opposed to two-ventricle physiology where blood flow is in-series. Ideally, blow flow should have a similar ratio in both circulation systems, i.e., Qp:Qs at 1:1.

In the Norwood anatomy and physiology, there is mixing of blood due to atrium septum. As a result, the typical arterial oxygen saturation values in these children are in the range of $75-85 \%$. Such lower arterial oxygen saturation values (as compared with normal individuals) are surprisingly well-tolerated.

The source of pulmonary blood flow (PBF) by using a Gore-Tex(polytetrafluorethylene) tube implanted between the right innominate or subclavian artery and the right pulmonary artery constitute modifications of the BlalockTaussig (B-T) shunt. The modification is based on a description by Alfred Blalock and Helen Taussig in 1945 [13, 14]. This modified shunt is known as the MBT shunt. The shunt is typically $3.5 \mathrm{~mm}$ in diameter, so that there is optimal flow and excessive flow to the lung is avoided. The MBT shunt allows for blood flow also in diastolic phase into the pulmonary vasculature and away from the coronary perfusion, which gives rise to development of the coronary steal phenomenon. As a result, there is volume load on the single ventricle and a decreased myocardial function, arrhythmias, and sudden cardiac death [15]. Acute shunt thrombosispartial or total-is also a possible complication which may generate life-threatening hypoxemia [16]. To regulate these detrimental physiological features, as an alternative to the MBT shunt, the RV-PA shunt was developed.

Anastomosis between the right ventricle and pulmonary artery trunk is known as the RV-PA shunt, located on the right or left side of reconstruction of the neoaorta. Norwood and colleagues initially described the RV-PA conduit, but the reported method was long ignored [17]. Earlier, there had been many attempts at creating a RV-PA shunt in single ventricle patients [18-20].The RV-PA conduit has seen a dramatic revival in popularity since its re- 
introduction by Sano [21]. RV-PAs have an advantage as compared to MBT shunt because it prevents coronary steal during diastole that could potentially contribute to the improvement of treatment outcomes in the interstage period $[22,23]$. The RV-PA shunt requires a right ventriculotomy and the non-valved nature of the conduit may lead to regurgitant flow, which could potentially lead to ventricular dysfunction in an already stressed univentricular heart. These disadvantages may cause ventricular arrhythmias and impair the systemic right ventricle function [24]. The choice between these two sources of PBF is currently surgeon or institution-dependent.

Many single institutions published articles, comparing the traditional B-T shunt vs. the RV-to-PA conduit [25, 26]. Because of the conflicting results and limitations due to single-center retrospective studies, trials were needed for solving this question. The Pediatric Heart Network published a multicenter randomized trial in infants with HLHS undergoing the Norwood procedure, known as the Single Ventricle Reconstruction (SVR) trial [27]. In this trial, 555 patients were randomized to either a MBT shunt or an RV-PA conduit groups. There were 72 deaths or cardiac transplants in the RV-PA shunt group, and 100 deaths or cardiac transplants in the MBT shunt group. On the basis of the data, the RV-PA shunt as compared to the MBT was found to be associated with an improved transplantation-free survival at 12 months.

Two studies from SVR trials described in-hospital and inter-stage mortality associated with the Norwood procedure as being $16 \%$ irrespectively of shunt type. The interstage mortality between stage I and II was $6 \%$ for the RVPA conduit, and $18 \%$ for the MBT shunt. The 3-year follow-up for transplant-free survival in the SVR trial did not differ by shunt types [28].

The most recent study identified an association between digoxin and reduced mortality following hospital discharge after the Norwood procedure using SVR data [29].

A study that investigated preoperative risk factors, using the database from the Society of Thoracic Surgeons, found that weight below $2.5 \mathrm{~kg}$, preoperative shock, non-cardiac or genetic abnormalities, preoperative mechanical ventilatory or circulatory support, a small ascending aorta, an intact/restrictive interatrial septum, and the variant of HLHS with aortic atresia and mitral stenosis led to postoperative complications [30].

In a recent study from the Congenital Heart Surgeon's Society, the propensity scores were used to compare 169 RV-PA conduit with 169 MBT shunt patients. There was better 6-year survival with the RV-PA $(70 \%)$ conduit versus the MBT shunt (55\%). The MBT shunt showed a lower transplant-free survival and right ventricular dysfunction with moderate to severe atrioventricular valvular regurgitation [31].

\section{Hybrid procedures}

The hybrid procedure represents a less intensive approach that combines interventional cardiac catheterization with offcardiopulmonary bypass surgery, first reported in 1993 [32]. Cardiopulmonary bypass use in neonates with cardiac and non-cardiac comorbidities might lead to neurological complications; thus, an alternative to CBP became the origin of hybrid approach in HLHS patients.

The hybrid procedure achieves the same goals as the standard Norwood procedure in a less intensive manner, which can be described as follows:

i. systemic perfusion is maintained with a ductal arteriosus stent.

ii. unrestricted pulmonary venous return is accomplished with either surgical atrial septectomy or a balloon atrial septostomy.

iii. controlled (diminished) PBF is accomplished with pulmonary artery bands on the right and the left pulmonary artery.

After the inter-stage period, the comprehensive stage I + II includes the removal of the PA bands, removal of the ductal stent, and repair of the aortic arch and pulmonary arteries. Removing the ductal stent is probably the most challenging element. It takes a technique similar to an endarterectomy to safely extract the stent without injuring the descending thoracic aorta. Initially, the hybrid approach was used for high-risk infants. With formal or relative contraindications to the Norwood stage I operation, single-center studies showed the feasibility of the approach, and others started using it on standard risk patients as an alternative to the Norwood stage I procedure [33].

The pioneering work by Galantowicz and colleagues [34] was very illustrative in demonstrating what can be accomplished with the hybrid approach for HLHS. Sixty-two patients underwent the hybrid stage I procedure. The results were impressive, with the hospital survival after the hybrid stage I reaching $97.5 \%$. In the inter-stage I-II interval, two patients died. The hospital survival during the comprehensive stage I + II was $92 \%$. The most important point derived from this early experience is that in certain patients with unfavorable anatomy, namely those with aortic atresia and no antegrade flow to the coronary arteries, jailing by the ductal stent may create stenosis of the retrograde orifice to the transverse arch. These patients should be identified before intervention, because a ductal stent can acutely lead to head vessel and/or coronary artery flow compromise, potentially leading to death from myocardial infarction and circulatory collapse. The options are to offer these patients the standard Norwood procedure or to stent the retrograde orifice at the time of the patent ductus arteriosus (PDA) stent [35]. 
The group in Giessen recently described 182 babies that underwent this hybrid strategy [36]. At 10 years, the probability of survival is $77.8 \%$. Aortic arch re-interventions were only needed in $16.7 \%$ of patients. A benefit of this approach was that several of the patients were able to be transitioned to the biventricular repair after the hybrid approach instead of the single ventricle palliation.

\section{Hybrid-bridge-to-Norwood}

The need for more catheterizations and the concerns about removing the stent during the comprehensive stage I + II led to the revival of another sequence of operations once described by Dr. Norwood, called the hybrid-bridge-toNorwood or the "salvage-bridge-to-Norwood" [37]. In highrisk HLHS neonates with concomitant cardiac and noncardiac comorbidities, in whom the initial Norwood stage I operation is deemed prohibitive, the sequence starts with bilateral pulmonary artery bands in the early period after birth. The ductus is kept open with prostaglandins, instead of a mechanical stent. The Norwood stage I is then performed after the baby is stabilized, typically at about 2 weeks of age. The "hybrid-bridge-to-Norwood" or "salvage-to-Norwood" approach gives the baby time to recover and allows time for the surgeon to undertake the Norwood stage I at a more advantageous moment. Although the in-hospital mortality with the "salvage-to-Norwood" approach is high as compared to other approaches in neonates with HLHS, it is the only alternative to certain death in an otherwise very high-risk and unstable situation.

\section{Inter-stage period}

The period of time between hospital discharge after the Norwood procedure and the stage II surgery is commonly referred to as the inter-stage period. During the inter-stage period, accurate monitoring of the patient and cardiologic examination is important. After implementing parental education and home monitoring program (measuring systemic blood oxygenation with pulse oximeter, and changes in weight), there is a reduced complication rate and better survival [38]. Mortality between stages is $4-15 \%$. The main causes of death are as follows: ventricular dysfunction, stenosis of the carotid artery or aortic arch, restriction of the atrial septum, coronary circulation disorders, and stenosis or systemic-pulmonary systemic obstruction [39].

The most common re-interventions after the first stage of treatment are also associated with problems. Stenosis of the aorta appears with an incidence of about 5-10\% and in the majority of cases, it is effectively resolved by the method of transcutaneous balloon plastic surgery. Invasive cardiology techniques are also used for implantation of stents into the formation of stenosis of the anastomosis. Tricuspid valve surgery and interventions within pulmonary stenosis are performed during the second stage of treatment [35].

\section{Second stage of treatment}

Currently, two basic surgical techniques are used: the hemiFontan operation or bidirectional Glenn anastomosis. The energy loss in the lateral intra-atrial tunnel (the third stage of treatment) produced after the previous hemi-Fontan operation is significantly lower compared to the energy dissipation in the tunnel produced after Glenn's two-way operation. More physiological distribution of blood to both lungs after the hemi-Fontan surgery has been also noted [40]. The second stage of treatment after previous treatment hybridization is a more complicated and longer operation. It is a combination of the Norwood operation and hemi-Fontan operation and in some centers also serves as preparation for performing the third stage of invasive cardiological defect treatment [34].

The Norwood procedure is undertaken during the time when the pulmonary vascular resistance is too elevated to allow a cavopulmonary anastomosis. The second stage is usually undertaken between 4 and 6 months of age. The goal of the second stage is to unload the right ventricle. This is accomplished with either the bidirectional Glenn or the hemiFontan. The advantage of the bidirectional Glenn is that it can potentially be performed off-pump and is an easier connection. The hemi-Fontan makes the final stage more straightforward. This second stage originally was proposed as an interim palliation only for high-risk babies before undergoing the Fontan operation [41], instead of proceeding directly from a shunted physiology to total cavopulmonary connection (TCPC) in one step, which is a huge physiological change associated with a high risk of failure. After the staged palliation with the interim Glenn operation, breaking the adaptation to new cardiopulmonary flows into two lower-risk steps with better results, the Glenn operation became a standard staging procedure even in babies with a low-risk profile, leading to the current three-stage approach. The goal is to unload the ventricle as early as possible, minimize the potential steal from coronary blood flow, and limit the amount of time the pulmonary vasculature is exposed to systemic pressures before the baby can tolerate the Fontan [42].

Traditionally, the bidirectional Glenn anastomosis was situated between the superior vena cava and the pulmonary arteries. The inferior vena cava to pulmonary artery anastomosis was abandoned in the animal lab by Dr. Glenn after repeated failures in his animal models. In patients with unfavorable upper body systemic venous anatomy, the superior vena cava (SVC)-pulmonary artery (PA) connection is suboptimal or not feasible, and an alternative is needed to unload the heart. As it 
Table 1 The sequential surgical procedures for single-ventricle palliation (SVP)

\begin{tabular}{|c|c|}
\hline Study name & The sequential surgical procedures \\
\hline Emani et al. 2012 [50] & $\begin{array}{l}\text { Stage } 1 \text { - > BDG - > Fotan - > cardiac transplantation } \\
\text { OR } \\
\text { Stage } 1 \text { - > BDG - > biventricular conversion - > cardiac transplantation. }\end{array}$ \\
\hline Malec et al. 2000 [51] & Stage 1 with mBTS - > stage II (hemi-Fontan) and stage III (modified Fontan). \\
\hline McGuirk et al. 2006 [52] & Norwood procedure - > bidirectional Glenn procedure (stage II) - > a modified Fontan procedure (stage III) \\
\hline Andrews et al. [53] & $\begin{array}{l}\text { stage I (the Norwood operation) - > stage II (the hemi-Fontan operation - > } \\
\text { stage III (the Fontan operation - > cardiac transplantation }\end{array}$ \\
\hline Rogers et al. 2012 [54] & $\begin{array}{l}\text { stage I (mBTS) - > stage II (BDG) - > stage III extracardiac conduit (ECC) Fontan - > cardiac transplantation } \\
\text { or } \\
\text { stage I (RV-PA)- > stage II (the hemi-Fontan operation - > stage III (the Fontan operation - > cardiac transplantation }\end{array}$ \\
\hline Malec et al. 2017 [55] & $\begin{array}{l}\text { stage I (mBTS) - > stage II (BDG) - > stage III extracardiac conduit (ECC) Fontan - > cardiac transplantation } \\
\text { or } \\
\text { stage I (RV-PA)- > stage II (the hemi-Fontan operation - > stage III (the Fontan operation - > cardiac transplantation }\end{array}$ \\
\hline Rai et al. 2018.[56] & stage I (RV-PA)- > stage II (the hemi-Fontan operation - > stage III (the Fontan operation - > cardiac transplantation \\
\hline
\end{tabular}

$B D G$ bidirectional Glenn procedure, $m B T S$ modifed right Blalock-Taussig shunt, $E C C$ extracardiac conduit, $I A L T$ intra-atrial lateral tunnels, $H F$ hemiFontan, $R V$ - $P A$ the right ventricle-to-pulmonary artery shunt

was demonstrated by studies, this subset of patients may benefit from the primary inferior vena cava (IVC)-pulmonary artery (PA) connection, the "Southern Glenn," which we have performed successfully in two patients [43].

\section{Third stage of treatment-Fontan procedure}

The Fontan operation typically connects the IVC to the right pulmonary artery (RPA) leading to a total cavopulmonary connection so that all PBF is achieved passively. In-series circulation is restored and saturation achieves near-normal levels. This typically happens between 24 and 48 months of age. There are numerous single institution series investigating the short- and long-term outcomes and predictors of mortality and morbidity after the Fontan completion [44, 45]. The consistent predictors of poor outcome across multiple studies are longer cross-clamp times, longer duration of hospital stay, heterotaxy, and atrioventricular valve anomaly.

The concept of the Fontan operation was first applied to a patient with tricuspid atresia by Francis Fontan in 1968 [46], but it has since become the final surgical stage for patients with HLHS. The goal of this ingenious operation is to direct the desaturated systemic venous return from the inferior vena cava into the pulmonary circulation, which may be done either via a lateral tunnel or extracardiac conduit that connects the inferior vena cava to the pulmonary artery. In some patients, small fenestration may be created in the Fontan conduit, a modification aimed at providing children with this unique anatomy and physiology with another means to fill their single ventricle, albeit with desaturated blood [47]. This practice may be especially helpful in patients with relatively high pulmonary vascular pressure values, although studies attempting to discern the merits of these theoretical benefits have been conflicting $[47,48]$.

Total venous-pulmonary connection may also be done by intervention cardiology via a polytetrafluorethylene-covered stent (covered stent) [49]. Balloon expansion under the control of angiography and echocardiography allows for an accurate placement of the stent in the correct position. This procedure requires prior preparation in II stage of treatment. The advantage is it may be done without ECMO support.

The strategy of using hybrid procedures will apply to few subsets and will not be a norm. Moreover, majority of centers are not very comfortable with Norwood Glen at stage 2 with retrieval of the stent to repair the arch which seems possible but likely to have sequels as arch obstruction and pulmonary artery plasty following the bilateral PA bands, pulmonary artery anatomy being the most important factor for influencing the outcome of the single ventricle repair. The sequential surgical procedures with good outcomes practiced in a good number of centers in the world are presented in (Table 1).

An unsolvable problem remains in any path taken (Surgical/interventional/Hybrid), for the staged palliation which is a ventricular function which is the real Achilles heel of these repairs. The possibility of use of a ventricular pump in future might be a reality to sort out this issue.

\section{Conclusions}

There are widespread modifications of the Norwood operations which significantly improve HLHS results. Early diagnostic management, prenatal interventions, innovative diagnostic methods, constantly modified surgical techniques, and hybridization contribute to a significant progress in treatment 
options. This will allow for defining an optimal strategy of improving survival and quality of life in HLHS patients. The world experience and a lot of the available literature say that. The 1st-stage procedure could be done now safely either directly or with a bridge to Norwood followed by the stage 2 with a Glen or Hemi-Fontan and followed by a Fontan down the lane surgically.

\section{Compliance with ethical standards}

Patient consent Not required. The review did not involve any Human Participants and/or Animals.

Conflict of interest The authors declare that they have no conflicts of interest.

Open Access This article is distributed under the terms of the Creative Commons Attribution 4.0 International License (http:// creativecommons.org/licenses/by/4.0/), which permits unrestricted use, distribution, and reproduction in any medium, provided you give appropriate credit to the original author(s) and the source, provide a link to the Creative Commons license, and indicate if changes were made.

\section{References}

1. Hoffman JI, Kaplan S. The incidence of congenital heart disease. J Am Coll Cardiol. 2002;39:1890-900.

2. Rychik J, Szwast A, Natarajan S, et al. Perinatal and early surgical outcome for the fetus with hypoplastic left heart syndrome: a fiveyear single institutional experience. Ultrasound Obstet Gynecol. 2010;36:465-70.

3. Mahle W, Clancy RR, McGaurn SP, Goin JE, Clark BJ. Impact of prenatal diagnosis on survival and early neurologic morbidity in neonates with the hypoplastic left heart syndrome. Pediatrics. 2001;107:1277-82.

4. Allan LD, Cook A, Sullivan I, Sharland GK. Hypoplastic left heart syndrome: effects of fetal echocardiography on birth prevalence. Lancet. 1991;337:959-61.

5. Tworetzky W, Wilkins-Haug L, Jennings RW, et al. Balloon dilation of severe aortic stenosis in the fetus: potential for prevention of hypoplastic left heart syndrome: candidate selection, technique,and results of successful intervention. Circulation. 2004;110:2125-31.

6. Cox H, Wilson DI. The genetics of hypoplastic left heart syndrome. Fetal Matern Med Rev. 2007;18:103-20.

7. Chiavarelli M, Gundry SR, Razzouk AJ, Bailey LL. Cardiac transplantation for infants with hypoplastic left heart syndrome. JAMA. 1993;270:2944-7.

8. West LJ, Pollock-Barziv SM, Dipchand AI, et al. ABO-incompatible heart transplantation in infants. N Engl J Med. 2001;344:793800 .

9. Boucek MM, Edwards LB, Keck BM, et al. The Registry of the International Society for Heart and Lung Transplantation: Fifth Official Pediatric Report: 2001 to 2002. J Heart Lung Transplant. 2002;21:827-40.

10. Mitchell MB, Campbell DN, Boucek MM. Heart transplantation for the failing Fontan circulation. Semin Thorac Cardiovasc Surg Pediatr Card Surg Ann. 2004;7:56-64.

11. Kołcz J, Skalski J. Contemporary strategies of the hypoplastic left heart syndrome treatment. Kardiol Pol. 2011;69:275-80.
12. Mahle WT, Spray TL, Wernovsky G, Gaynor JW, Clark BJ 3rd. Survival after reconstructive surgery for hypoplastic left heart syndrome: a 15 -year experience from a single institution. Circulation. 2000;102:III136-41.

13. Blalock A, Taussig HB. The Surgical treatment of malformations of the heart in which there is pulmonary stenosis or pulmonary atresia. JAMA. 1945;128:189-202.

14. Murphy AM, Cameron DE. The Blalock-Taussig-Thomas collaboration: a model for medical progress. JAMA. 2008;300:328-30.

15. Donnelly JP, Raffel DM, Shulkin BL, et al. Resting coronary flow and coronary flow reserve in human infants after repair or palliation of congenital heart defects as measured by positron emission tomography. J Thorac Cardiovasc Surg. 1998;115:103-10.

16. Bartram U, Grünenfelder J, Van Praagh R. Causes of death after the modified Norwood procedure: a study of 122 postmortem cases. Ann Thorac Surg. 1997;64:1795-802.

17. Norwood WI, Lang P, Casteneda AR, Campbell DN. Experience with operations for hypoplastic left heart syndrome. J Thorac Cardiovasc Surg. 1981;82:511-9.

18. Pizarro C, Malec E, Maher KO, et al. Right ventricle to pulmonary artery conduit improves outcome after stage I Norwood for hypoplastic left heart syndrome. Circulation. 2003;108:II155-60.

19. Kishimoto H, Kawahira Y, Kawata H, Miura T, Iwai S, Mori T. The modified Norwood palliation on a beating heart. J Thorac Cardiovasc Surg. 1999;118:1130-2.

20. Imoto Y, Kado H, Shiokawa Y, Minami K, Yasui H. Experience with the Norwood procedure without circulatory arrest. J Thorac Cardiovasc Surg. 2001;122:879-82.

21. Sano S, Ishino K, Kado H, et al. Outcome of right ventricle-topulmonary artery shunt in first-stage palliation of hypoplastic left heart syndrome: a multi-institutional study. Ann Thorac Surg. 2004;78:1951-7.

22. Januszewska K, Kozlik-Feldmann R, Abicht J, Dalla-Pozza R, Malec E. Right ventricle- to-pulmonary artery shunt in norwood procedure: early results. World J Pediatr Congenit Heart Surg. 2010;1:44-50.

23. Pizarro C, Mroczek T, Malec E, Norwood WI. Right ventricle to pulmonary artery conduit reduces interim mortality after stage 1 Norwood for hypoplastic left heart syndrome. Ann Thorac Surg. 2004;78:1959-63.

24. Frommelt PC, Gerstenberger E, Cnota JF, et al. Impact of initial shunt type on cardiac size and function in children with single right ventricle anomalies before the Fontan procedure: the single ventricle reconstruction extension trial. J Am Coll Cardiol. 2014;64: 2026-35.

25. Mair R, Tulzer G, Sames E, et al. Right ventricular to pulmonary artery conduit instead of modified Blalock-Taussig shunt improves postoperative hemodynamics in newborns after the Norwood operation. J Thorac Cardiovasc Surg. 2003;126:1378-84.

26. Mahle WT, Cuadrado AR, Tam VK. Early experience with a modified Norwood procedure using right ventricle to pulmonary artery conduit. Ann Thorac Surg. 2003;76:1084-8.

27. Ohye RG, Sleeper LA, Mahony L, et al. Comparison of shunt types in the Norwood procedure for single-ventricle lesions. N Engl J Med. 2010;362:1980-92.

28. Newburger JW, Sleeper LA, Frommelt PC, et al. Transplantationfree survival and interventions at 3 years in the single ventricle reconstruction trial. Circulation. 2014;129:2013-20.

29. Oster ME, Ehrlich A, King E, et al. Association of interstage home monitoring with mortality, readmissions, and weight gain: a multicenter study from the National Pediatric Cardiology Quality Improvement Collaborative. Circulation. 2015;132:502-8.

30. Hornik CP, He X, Jacobs JP, et al. Complications after the Norwood operation: an analysis of The Society of Thoracic Surgeons Congenital Heart Surgery Database. Ann Thorac Surg. 2011;92: $1734-40$. 
31. Wilder TJ, McCrindle BW, Phillips AB, et al. Survival and right ventricular performance for matched children after stage-1 Norwood: Modified Blalock-Taussig shunt versus right-ventricleto-pulmonary-artery conduit. J Thorac Cardiovasc Surg. 2015;150: 1440-50.

32. Gibbs JL, Wren C, Watterson KG, Hunter S, Hamilton JR. Stenting of the arterial duct combined with banding of the pulmonary arteries and atrial septectomy or septostomy: a new approach to palliation for the hypoplastic left heart syndrome. Br Heart J. 1993;69:551-5.

33. Pizarro C, Murdison KA. Off pump palliation for hypoplastic left heart syndrome: surgical approach. Semin Thorac Cardiovasc Surg Pediatr Card Surg Annu. 2005;7:66-71.

34. Galantowicz M, Cheatham JP, Phillips A, et al. Hybrid approach for hypoplastic left heart syndrome: intermediate results after the learning curve. Ann Thorac Surg. 2008;85:2063-70.

35. Akintuerk H, Michel-Behnke I, Valeske K, et al. Stenting of the arterial duct and banding of the pulmonary arteries: basis for combined Norwood stage I and II repair in hypoplastic left heart. Circulation. 2002;105:1099-103.

36. Yerebakan C, Valeske K, Elmontaser H, et al. Hybrid therapy for hypoplastic left heart syndrome: Myth, alternative, or standard? J Thorac Cardiovasc Surg. 2016;151:1112-21.

37. Dodge-Khatami A, Chancellor WZ, Gupta B, et al. Achieving Benchmark Results for Neonatal Palliation of Hypoplastic Left Heart Syndrome and Related Anomalies in an Emerging Program. World J Pediatr Congenit Heart Surg. 2015;6:393-400.

38. Ghanayem NS, Hoffman GM, Mussatto KA, et al. Home surveillance program prevents interstage mortality after the Norwood procedure. J Thorac Cardiovasc Surg. 2003;126:1367-77.

39. Hehir DA, Dominguez TE, Ballweg JA, et al. Risk factors for interstage death after stage 1 reconstruction of hypoplastic left heart syndrome and variants. J Thorac Cardiovasc Surg. 2008;136:94-9.

40. Bove EL, de Leval MR, Migliavacca F, Guadagni G, Dubini G. Computational fluid dynamics in the evaluation of haemodynamic performance of cavopulmonary connections after the Norwood procedure for hypoplastic left heart syndrome. J Thorac Cardiovasc Surg. 2003;126:1040-7.

41. Bridges ND, Jonas RA, Mayer JE, Flanagan MF, Keane JF, Castaneda AR. Bidirectional cavopulmonary anastomosis as interim palliation for high-risk Fontan candidates. Early results. Circulation. 1990;82:IV170-6.

42. Jaquiss RD, Ghanayem NS, Hoffman GM, et al. Early cavopulmonary anastomosis in very young infants after the Norwood procedure: impact on oxygenation, resource utilization, and mortality. J Thorac Cardiovasc Surg. 2004;127:982-9.
43. Dodge-Khatami A, Aggarwal A, Taylor MB, Maposa D, Salazar JD. When the bi-directional Glenn is an unfavourable option: inferior cavopulmonary connection as an alternative palliation. Cardiol Young. 2015;28:1-3.

44. Stamm C, Friehs I, Mayer JE Jr, et al. Long-term results of the lateral tunnel Fontan operation. J Thorac Cardiovasc Surg. 2001;121:28-41.

45. Mosca RS, Kulik TJ, Goldberg CS, et al. Early results of the fontan procedure in one hundred consecutive patients with hypoplastic left heart syndrome. J Thorac Cardiovasc Surg. 2000;119:1110-8.

46. Fontan F, Baudet E. Surgical repair of tricuspid atresia. Thorax. 1971;26:240-8.

47. Lemler MS, Scott WA, Leonard SR, Stromberg D, Ramaciotti C. Fenestration improves clinical outcome of the fontan procedure: a prospective, randomized study. Circulation. 2002;105:207-12.

48. Hsu DT, Quaegebeur JM, Ing FF, Selber EJ, Lamour JM, Gersony WM. Outcome after the single-stage, nonfenestrated Fontan procedure. Circulation. 1997;96:335-40.

49. Sallehuddin A, Mesned A, Barakati M, Fayyadh MA, Fadley F, AlHalees Z. Fontan completion without surgery. Eur J Cardiothorac Surg. 2007;32:195-200.

50. Emani SM, McElhinney DB, Tworetzky W, et al. Staged Left Ventricular Recruitment After Single-Ventricle Palliation in Patients With Borderline Left Heart Hypoplasia. J Am Coll Cardiol. 2012;60:1966-74.

51. Malec E, Januszewska K, Kołz J, Pajak J. Factors influencing early outcome of Norwood procedure for hypoplastic left heart syndrome. Eur J Cardiothorac Surg. 2000;18:202-6.

52. McGuirk SP, Griselli M, Stumper OF, et al. Staged surgical management of hypoplastic left heart syndrome: a single institution 12 year experience. Heart. 2006;92:364-70.

53. Andrews R, Tulloh R, Sharland G, et al. Outcome of staged reconstructive surgery for hypoplastic left heart syndrome following antenatal diagnosis. Arch Dis Child. 2001;85:474-7.

54. Rogers LS, Glatz AC, Ravishankar C, et al. 18 Years of the Fontan Operation at a Single Institution :Results From 771 Consecutive Patients. J Am Coll Cardiol. 2012;60:1018-25.

55. Malec E, Schmidt C, Lehner A, Januszewska K. Results of the Fontan operation with no early mortality in 248 consecutive patients. Kardiol Pol. 2017;75:255-60.

56. Rai V, Mroczek T, Szypulski A, et al. Outcome of Norwood operation for hypoplastic left heart syndrome. Indian $\mathrm{J}$ Thorac Cardiovasc Surg. 2018;34:337-44. 